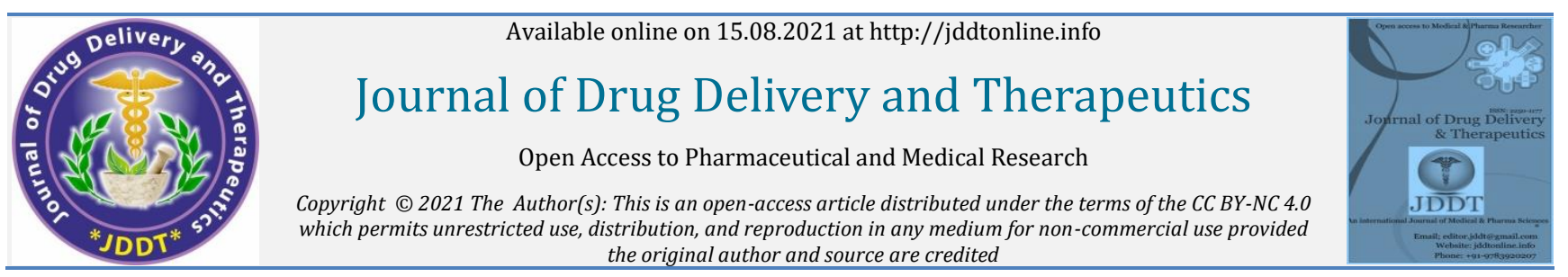

Open Access Full Text Article the original author and source are credited
and

\title{
Development and Validation of TLC of Flavonoid from the Ethanolic Extract of Plant Enhydra fluctuans
}

\author{
Pahari Sandip Kumar*, Panda Shambo, Manna Sourav, Mukhopadhyaya Projjal, Mahato Ujjal, Biswal Bishnupada \\ Bharat Technology, Banitabla, Uluberia, Howrah, West Bengal, India
}

Article Info:

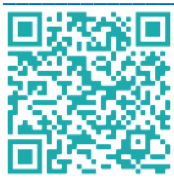

\section{Article History:}

Received 08 June 2021

Reviewed 13 July 2021

Accepted 21 July 2021

Published 15 August 2021

\section{Cite this article as:}

Pahari SK, Panda S, Manna S, Mukhopadhyaya P Mahato U, Biswal B, Development and Validation of TLC of Flavonoid from the Ethanolic Extract of Plant Enhydra fluctuans, Journal of Drug Delivery and Therapeutics. 2021; 11(4-S):36-41

DOI: http://dx.doi.org/10.22270/jddt.v11i4-S.4915

\section{*Address for Correspondence:}

Pahari Sandip Kumar, 34D/7 Anupama Housing Complex, VIP Road, PO-Airport, Kolkata 700052, India

\section{Abstract}

Thin layer chromatography is a technique or an analytical tool to separate the bioactive compound from the mixture of components. In current research work special attention was given to develop specific solvent system and to validate the principle of separation of Flavonoid. The ethanolic extract of plant namely Helencha (in Bengali) was selected for such purpose. After several trials, the presence of Flavonoid which was confirmed by qualitative evaluation and was sepahjvvrated successfully under this study and the process was validated under the circumstances of ICH Guideline. The plant not only contained Flavonoid but there were the presence of little quantity of Alkaloid, Saponin and Tannins also. Due to presence of Flavonoid the ethanolic fraction of the plant may be evaluated for Antiinflammatory and Anthelmintic activity for further research. The plant Helencha is known as Enhydra fluctuans belongs to the family Astereceae. According to folklore claim the plant is useful for nutrition purpose. Not only that the plant is also useful in Dropsy, anasarca and snake bite. As per the literature survey, the plant has Antioxidant and Analgesic activity. Here the total attention was given to separate Flavonoid from the mixture of Components present in the ethanolic fraction of the leaves of the plant.

Keywords: Flavonoid, Alkaloid, ICH Guideline, Enhydra fluctuans, Dropsy, Anaasrca.

\section{INTRODUCTION:}

TLC is one among the only, fastest, easiest and least expensive of several chromatographic techniques utilized in qualitative and quantitative chemical analysis to separate organic compounds and to check the purity of compounds. 1 TLC is a form of liquid chromatography consisting of a mobile phase (developing solvent) and a stationary phase (a plate or strip coated with a form of silica gel) - Analysis is performed on a flat surface under air pressure and room temperature.

Thin-layer chromatography (TLC) is an ideal technique for screening drugs, because of its low cost, easy maintenance, and the selectivity of detection reagents. TLC is highly suitable for the analysis of flavonoids, phenolic acids, and amino acids. Thin Layer Chromatography are often defined as a way of separation or identification of a mixture of components into individual components by using finely divided adsorbent solid / (liquid) spread over a glass plate and liquid as a mobile phase.

Principle: The separation principle of the TLC procedure is predicated on the given compound's relative affinity towards the mobile and therefore the stationary phase. The process begins here by moving the mobile phase over the stationary phase's surface. During this movement, higher affinity compounds gain less speed as compared to the lower affinity compounds. This results in their separation. ${ }^{2}$

Once the procedure gets completed, different spots are often found on the stationary surface at distinct levels, reflecting various elements of the mixture. Basically, the compounds that are more attracted towards the stationary phase secure their position at lower levels while others move towards the upper levels of the surface. So their spots can be seen accordingly.

Rf Value: After analysing the compound, it gets described in its relative mobility's terms, i.e., its $\mathrm{Rf}$ value is calculated. So as to make the technique more scientific rather than a mere interpretation by sight, what's called the Retention Value (Rf value for short) was applied in chromatography. A specific compound will travel the same distance along the stationary phase by a specific solvent (or solvent mixture) as long as other experimental conditions are kept constant. Usually, relative $\mathrm{Rf}$ comes into use here because keeping all the TLC factors constant won't be possible. These aspects include adsorbent, temperature, adsorbent thickness, spotted material's amount, and solvent system. In other words, every compound (dye, pigment, organic substance etc.) have a specific Rf value for every specific solvent and solvent concentration. Rf values come very handy for identification because one can compare Rf values of the 
unknown sample (or its constituents with Rf Values of known compounds. ${ }^{3}$

The Rf value is defined because the ratio of the space moved by the solute (i.e. the dye or pigment under test)
4 and thus the space moved by the solvent (known because the Solvent front) along the paper, where both distances are measured from the common Origin or Application Baseline, that is the purpose where the sample is initially spotted on the paper.

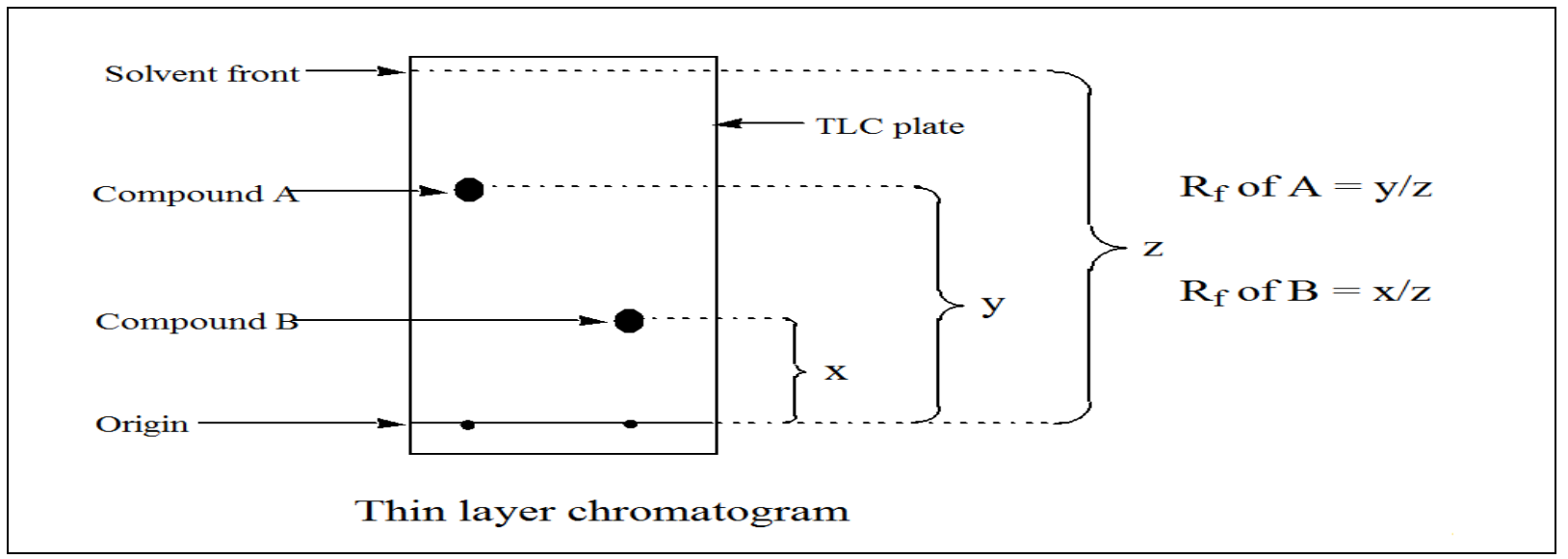

The formula of Rf value calculation is:

$\mathrm{Rf}=$ (Distance covered by the sample) / (Distance covered by solvent)

\section{Plant Profile:}

Scientific name: Enhydra fluctuans

Family: Asteraceae

Geographical prevalence: It grown in India, Bangladesh, Burma, Srilanka and a number of other place of SouthEast Asia. Helencha (Enhydra fluctuans) is a member of the family of Astereceae.

Introduction of Plant: Helencha (Enhydrafluctuans) is a member of the family of Astereceae vegetable.

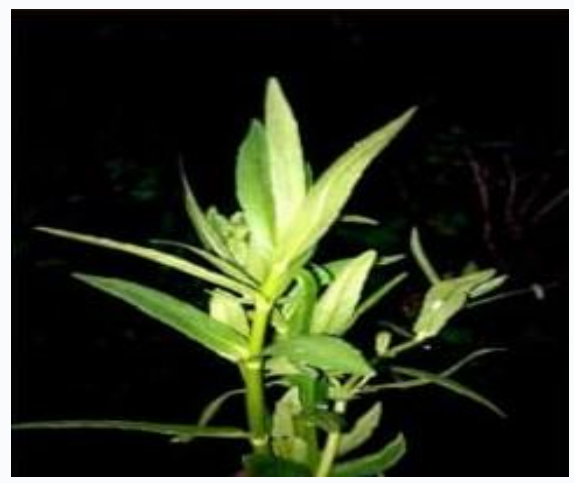

Figure 1: Enhydra fluctuans

It grown abundantly without much care and effort in water body land of India, Bangladesh, Burma, Srilanka and a number of other places ofSouth East Asia. Helencha is a prostrate herb with opposite sessile, linear oblong leaves, 1-3 inch long. The herbs is quite glabrous sometimes pubescent glandular, stems are 0.3-0.6 mm, elongated simple or divaricating rooting at the nodes. The lives are slightly bitter. Flowers are white or greenish white in colour.

Plant Description: Commonly known as Helencha or Enhydra or Marsh herb, it is a trailing marsh herb growing annually, also floating on water; stem $30-60 \mathrm{~cm}$ long, rooting at the nodes. Leaves are sessile, $2.5-2.7 \mathrm{~cm}$ in length, linear to oblong, acute or obtuse, and stalk-less and margins are distinctly dented. Flowers are white to greenish white in colour. Stems are fleshy, hairy and branched, 30 centimetre or more in length. Rooting can be seen at the lower nodes. The fruits are achenes enclosed by rigid receptacle-scales. Pappus is absent.

Traditional Use: Enhydra fluctuans is nutritious and used in ascites, dropsy, anasarca and snakebite. This plant has been reported to have anti-oxidative and analgesic activities. Some time it use as antianthelmintic. Some locality of India, juice of helencha use as laxative and skin protective for cure of skin disease, liver disease etc.

\section{Chemical Constituents \& Biological Action:}

Different extracts of Enhydra fluctuans have been tested for the presence or absence of primary and secondary bioactive compounds like carbohydrates, proteins, oils, alkaloids flavonoids to name a few. It has been rich source of flavonoids and moderate presence of alkaloids, tannins, phenolic and carbohydrate have been reported. $5,6,7$

\section{MATERIALS AND METHODS:}

Preparing the course powder of the shade dried leaves; it was subjected to soxhlet extraction using Petroleum Ether and then Ethanol respectively. Then the extract was evaluated for qualitative confirmation for the presence of Flavonoid. Then the attention was given to develop solvent system to separate Flavonoid from the mixture of components. First it was examined by different ratio of solvents as given in table. Finally the different trials were performed by hit and trial method to get sharp spot to ensure better separation and finally the total process of separation is validated. These total methods are described as below.

\section{- Materials}

Plant Material: Enhydra fluctuans course powder of leaves.

- Chemicals:

Petroleum ether, Ethanol

- Apparatus: 
Conical flask, Measuring cylinder, Soxhlet apparatus, Funnel, Beaker, Hot air oven, Heating mantle, RB flask, Distillation apparatus, Filter paper,

TLC chamber, Capillary tube, UV- cabinet etc

\section{Extraction procedure:}

The plant were separated from undesirable materials, cleaned by normal tap water, washed by distil water, remove the moisture by clean cloth and shaded dried in room temperature. After drying cut into small pieces and mixed by dry mixture grinder and produce a course powder. Remove moisture by hot air oven.

Air-dried and powdered aerial part of plant was extracted with petroleum ether $\left(60-80^{\circ} \mathrm{C}\right)$ followed by ethanol using Soxhlet apparatus. The solvent were removed under reduce pressure, sticky residues were obtained from Petroleum ether extract and then the crude ethanolic extract was prepared.

\section{Identification for flavonoid:}

We already know that the extracts of Enhydra fluctuans rich source of flavonoids, to confirm that we have done identification test for test solution. To perform this test (Enhydra fluctuans extract) we have added few drops of conc. sodium hydroxide solution which form of an intense yellow colour. This solution becomes Colourless on addition of few drops of conc. $\mathrm{HCl}$ acid, indicates presence of flavonoid. $8,9,1$

\section{Experimental design:-}

\section{Trial-1(combination of trials):}

Aim: As per the literature survey below mentioned mobile phase ratio had selected for the development of new TLC method by hit and trial, method.

Procedure: the different solvents of different polarity were subjected to develop the TLC for flavonoid. The several ratios of solvents were performed to develop a specific solvent system for the same. The different trials which were performed (Table: 1) to get a clear spot in TLC.

The ratios of solvent system are given below in tabular form:

Table: 1(Combinations of different solvent system)

\begin{tabular}{|l|l|l|}
\hline $\begin{array}{l}\text { Trial } \\
\text { number }\end{array}$ & Solvent taken & Ratio \\
\hline 1 & Chloroform: Ethyl acetate: Ethanol & $20: 30: 20$ \\
\hline 2 & Chloroform: Ethyl acetate: Ethanol & $30: 20: 30$ \\
\hline 3 & Chloroform: Ethyl acetate: Ethanol & $30: 30: 30$ \\
\hline 4 & Chloroform: Ethyl acetate: Ethanol & $40: 30: 30$ \\
\hline 5 & Chloroform: Ethyl acetate: Ethanol & $50: 20: 20$ \\
\hline 6 & Chloroform: Ethyl acetate: Ethanol & $40: 40: 30$ \\
\hline
\end{tabular}

Observation: Although we have tried different combinations of solvent systems but the clear and identified spots were not observed in most of the cases. But the solvent system which is given at the last of the table, Shows some degree of separation spots to some extent.

Conclusion: The solvent system having the ratio need to be further developed to get the more distinct, clear and specified spot by further trials given below.

\section{Trial-2}

Aim: As per the trial-1 the solvent system having the ratio need to be further developed to get the more distinct, clear and specified spot so we go with trial -2 mobile phase ratio had selected for the development of new TLC method for separation of flavonoid in Helencha plant .

Chloroform: Ethyl acetate: Ethanol $=40 \quad: \quad 40 \quad: \quad 20$

Procedure: We prepared the solvent system (mobile phase) with the above mentioned ratio (40:40:20) of the solvents. The mobile phase transferred into a development tank. Now we have taken a TLC plate and spot the sample solution with a capillary at $2 \mathrm{~cm}$ above from the bottom of the plate. Then have put the plate in the development tank and cover the development tank. Now we waited and watched for spots going upwards. Take the TLC plate out of the development tank when the solvent font is below $2 \mathrm{~cm}$ from the top

of the TLC plate. Then we tried to identify the spots developed.

Observation: No clear spot (Fig:2) detected for calculating Rf value.

Conclusion: From the Trial- 1 it is concluded by saying that the polarity of solvent systems need to be decreased.

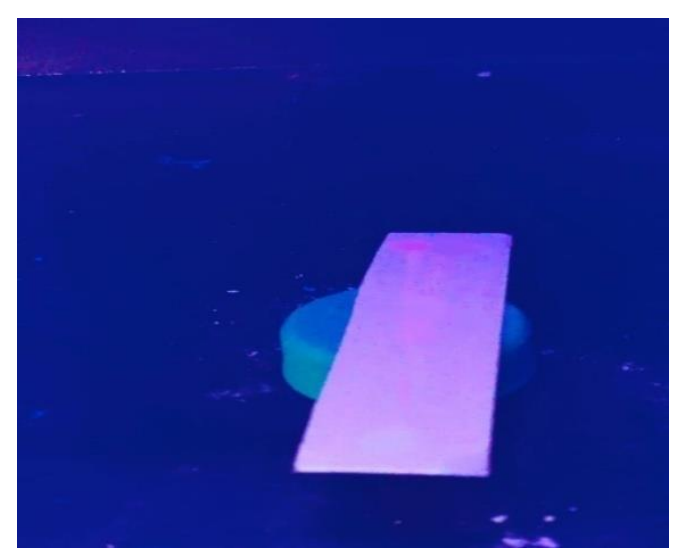

Figure 2: Trial: 2

Trial-3

Aim: we didn't observe any spot at trial-2, then we go with trial-3 and decreased the polarity of solvent system.

\section{Chloroform: Ethyl acetate: Ethanol}

$$
50: 20: 30
$$

Procedure: The ratio of solvents (50:20:30), we prepared for our mobile phase and then it was spoted sample in TLC plate with the help of capillary and place the TLC plate in development tank and cover the tank.

Observation: No clear spot (Fig:3) detected for calculating Rf value.

As we didn't observed in clear spot at trial-3, so we did the trial-4.

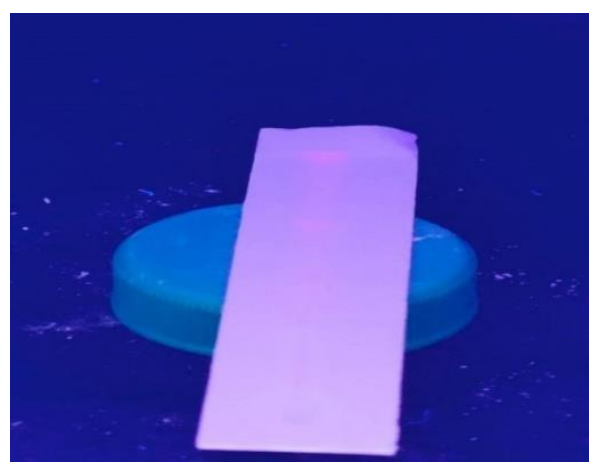

Figure 3: Trial:3 


\section{Trial-4}

\section{Chloroform: Ethyl acetate: Ethanol}

$40: 30: 30$

Procedure: The ratio of solvents (40:30:30), we prepared for our mobile phase and then spoted sample in TLC plate with the help of capillary and place the TLC plate in development tank and cover the tank and waited for development of spots.

Observation: No clear spot(Fig:4) detected for calculating Rf value.Trial-5: As wedidn't observed in clear spot at trial4 , so we did the trial- 5 and changed the solvent ratio.

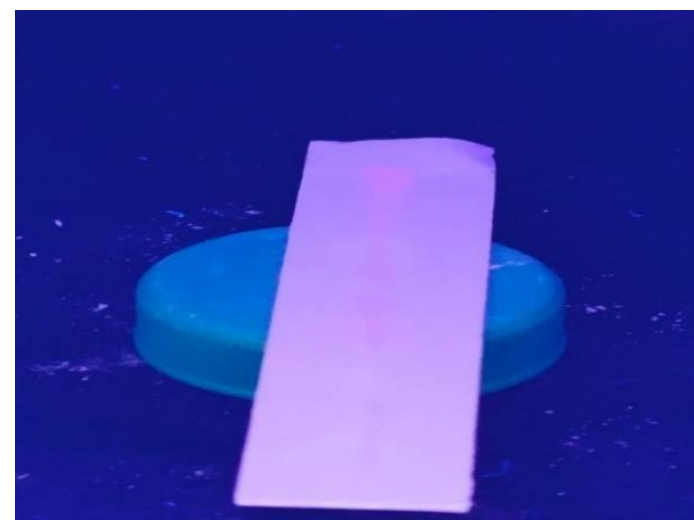

Figure 4: Trial:4

\section{Trial-5}

Chloroform: Ethyl acetate: Ethanol = $50: 30: 20$

Procedure: The solvent system was prepared as per the ratio described above and chromatogram was allowed to run.

Observation: No clear spot (Fig:5)detected for calculating Rf value.

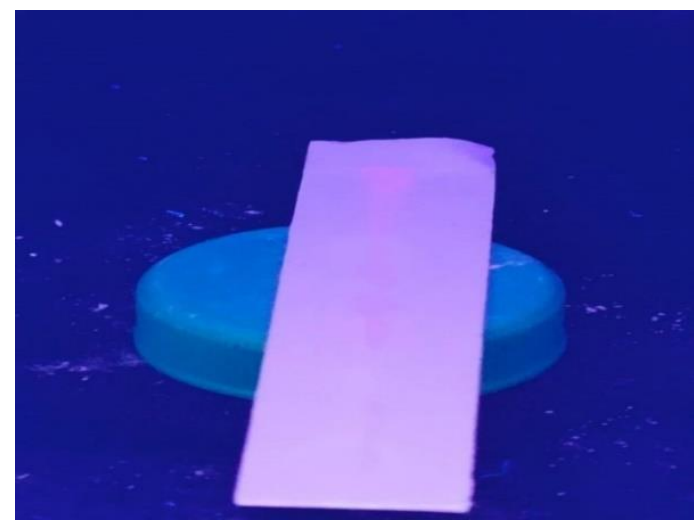

Figure 5: Trial:5

Trial-6

AS we didn't observed proper clear spot at trial-5, then we go with trial- 6 and increased the ratio of solvent system.

\section{Chloroform: Ethyl acetate: Ethanol}

$$
70: 20: 10
$$

Procedure: The ratio of solvents(70:20:10) we prepared for our mobile phase and then we added 2 to 3 drops of glacial aceticacid in the mobile phase and then spot sample in TLC plate with help of capillary and place the TLC plate in development tank and cover the tank and waited for the development of spots.

Observation: One unclear spot detected (Fig:6) but from this spot Rf value cannot be calculated.

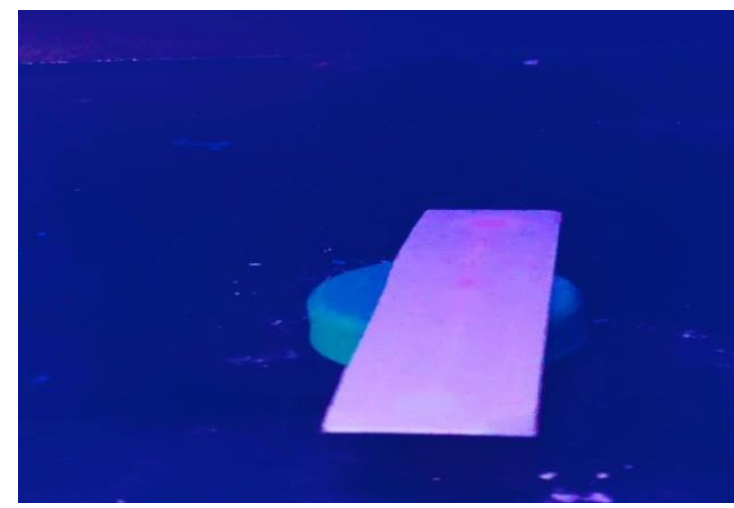

Figure 6: Trial:6

Trial-7

We didn't get any clear spot at trial-6 then we go with trial-7. Target is to achieve the proper TLC spot.

\section{Chloroform: Ethyl acetate: Ethanol}

$60: 20: 20$

Procedure: The ratio of solvents (60:20:20) we prepared for our mobile phase and added 2 to 3 drops of Glacial acetic acid in the mobile phase and then sample was spotted in TLC plate with help of capillary tube. Thenplatewas placed into the development tank and mouth was covered.

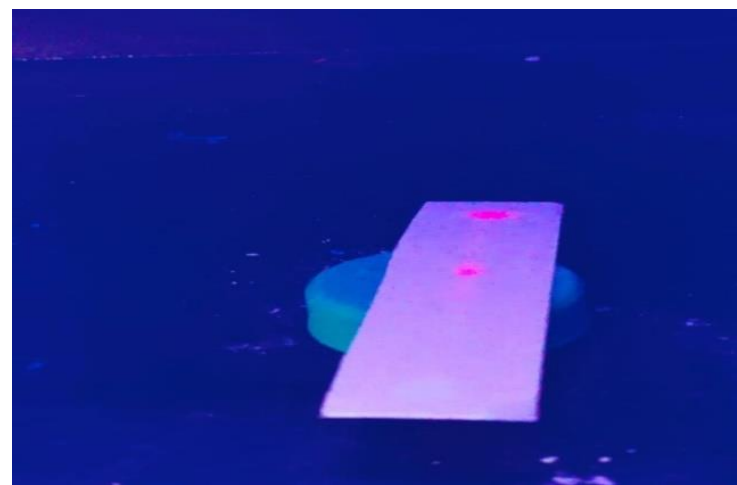

Figure 7: Trial:7

Observation: We get a clear spot (Fig:7) and from that we can calculate the Rf value.

Conclusion: From the Trial-7 it is concluded by saying that the clear spot detected, so this specimen will used for further study as well as for the determination of Rf Value.

\section{$R f$ value of the spot developed:}

By using forceps to delicately placed the TLC plate into the chamber. The liquid was not allowed to splash onto the plate. The liquid level was below the pencil line where the samples are spotted or the compounds will dissolve in the pool of eluent instead of traveling up the plate. The chamber covered by watch glass and kept it vertically, and don't touch it again until the TLC is complete. The TLC was allowed to develop, when the liquid moves towards the up of the TLC plate it will become transparent and wet. If the eluent is very polar (e.g. contains large amounts of ethanol or water), 
elution will take a relatively long time (can be 20-30 minutes). If the eluent is very nonpolar (e.g. contains large amounts of hexane or petroleum ether), elution will be relatively quick (can be $2-5$ minutes for a $10 \mathrm{~cm}$ tall plate). In our case the extract was diluted by the ethanol so it took little bit more time (18 -25 min) then the non-polar eluent.

\section{Calculation:}

Rf Value

$$
\begin{gathered}
=\frac{\text { Distance from Baseline travelled by Solute }(\mathrm{x})}{\text { Distance from Baseline travelled by Solvent (Solvent Front) }(\mathrm{y})} \\
=\frac{4.2}{6.5}=0.65
\end{gathered}
$$

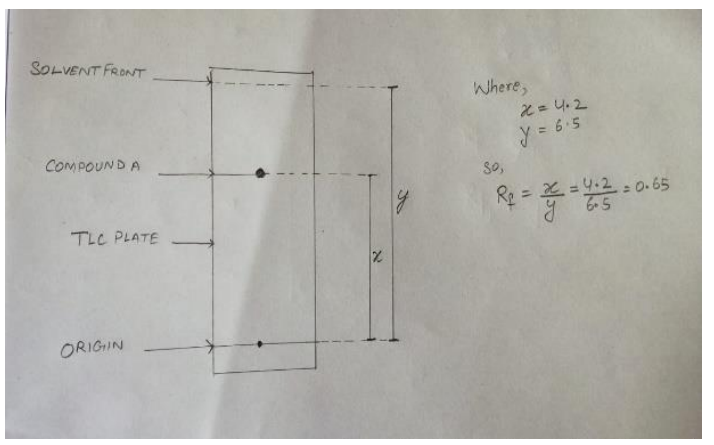

Figure 8: Calculation of Rf value

Conclusion: From the above ratio of the solvents, we get a clear spot-on TLC plate and from which we can calculate the $\mathrm{Rf}$ value. So new TLC method has developed for separation of flavonoid in halencha plant but the method need to be validated as per the ICH guideline. 12,13

\section{Validation:}

The proposed method was validated by specificity, precision according to the ICH guidelines Q2 (R1) and USP 1225. 12,13

1. Specificity: An investigation of specificity should be conducted during the validation of identification tests, the determination of impurities and the assay. The process used to manifest specificity will depend on the deliberate the objective of the analytical procedure. It is not always possible to manifest that an analytical process is specific for a particular analyte (complete discrimination). When this is happen thena combination of two or more analytical procedures is suggested to achieve the necessary level of discrimination.

Acceptance criteria: There should be no interference in sample spot from mobile phase and diluent.

Procedure: we had taken diluent (ethanol), sample solution and solvent (mobile phase) and put three spot in same TLC plate with the help of capillary tube and then by using forceps to delicately placed the TLC plate into the development chamber and not allowed the liquid to splash onto the plate. The liquid level was below the pencil line where the samples were spotted or the compounds will dissolve in the pool of eluent instead of traveling up the plate. The chamber covered by watch glass and kept it vertically, and don't touch it again until the TLC is complete. The TLC was allowed to develop, when the liquid moves towards the up the TLC plate it will become transparent.

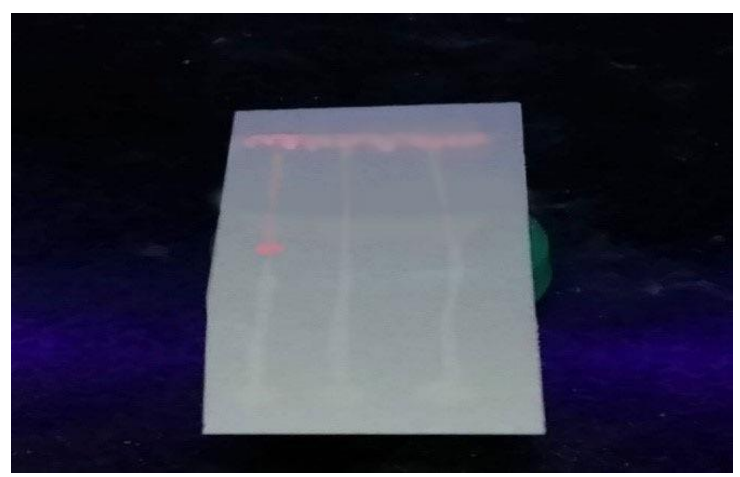

Figure 9: Specificity

Observation: There is nointerference (Fig:9) from mobile phase and diluent.

Conclusion: These are specific respect to the mobile phase and diluent.

\section{Precession:}

\section{Method Precision:}

(Day 1) date: $21 / 01 / 2021$

\section{Analyst Name: Sourav Manna}

Acceptance criteria: The $\mathrm{Rf}$ value of triplicated preparation should be comparable.

Procedure: we had taken sample solution and put triplicate spot in same TLC plate with the help of capillary tube and then by using forceps to delicately placed the TLC plate into the development chamber and not allowed the liquid to splash onto the plate.The liquid level was below the pencil line where the samples were spotted or the compounds will dissolve in the pool of eluent instead of traveling up the plate. The chamber covered by watch glass and kept it vertically, and don't touch it again until the TLC iscomplete. The TLC was allowed to develop, when the liquid moves towards the up the TLC plate it will become transparent.

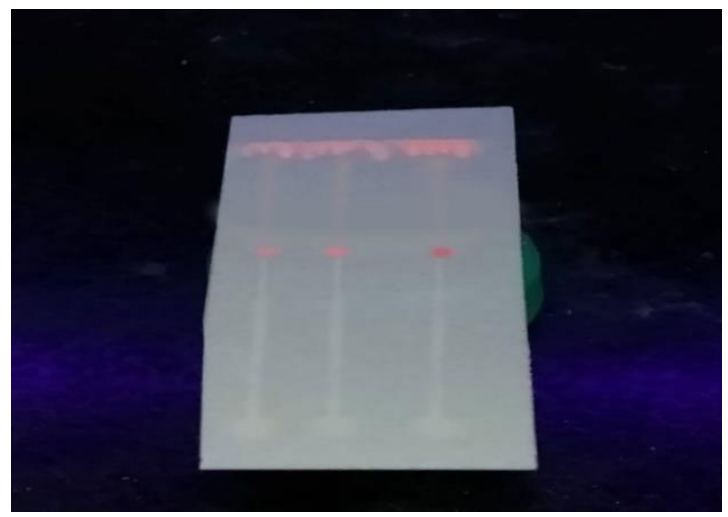

Figure 10: Method Precision

Observation: Three distinct spots are clearly visible and they are also comparable.

Conclusion: The method is précised in respect to method precision parameter.

(Day 2) date: $22 / 01 / 21$

\section{Intermediate Precession:}

\section{Analyst Name: Projjal Mukhopadhyaya}

Acceptance criteria: The Rf value of triplicated preparation should be comparable with method precision. 


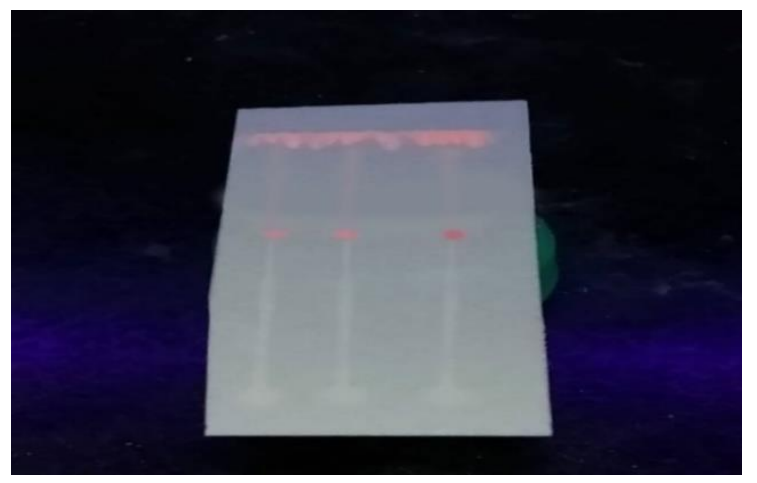

Figure 11: Intermediate Precession

Procedure: We had taken sample solution and put triplicate spot in same TLC plate using different Analyst in different day, with the help of capillary tube and then by using forceps to delicately placed the TLC plate into the development chamber and not allowed the liquid to splash onto the plate. The liquid level was below the pencil line where the samples were spotted or the compounds will dissolve in the pool of eluent instead of traveling up the plate. The chamber covered by watch glass and kept it vertically, and don't touch it again until the TLC is complete. The TLC was allowed to develop, when the liquid moves towards the up the TLC plate it will become transparent.

Observation: Three distinct spots are clearly visible and they are also comparable.

Conclusion: These are précised respect to different analyst and different day.

\section{RESULT AND DISCUSSIONS:}

After performing the several trials, the final combination of solvent system is obtained as, Chloroform: Ethyl acetate : Ethanol- 60:20:20. The corresponding Rf value is calculated as 0.65 . Now It may be said that from the ethanolic fraction of the plant Enhydra fluctuans the Flavonoid was separated successfully and the developed solvent system is validated as per some parameters of ICH guidelines.

\section{CONCLUSION:}

The TLC study on Enhydrae fluctuans extract indicates that of all applied chromatographic conditions, we had chooses most suitable Silica plate(silica gel $60 \mathrm{~F}_{254}$ ) as stationary phase and a mixture of chloroform : ethyl acetate : ethanol in volume compositions 60 :20:20 as mobile phase. Abovementioned chromatographic conditions resulted in optimum at trial-7. The Rf value we got 0.65 . This value confirmed the specificity of this methodology. According to the results of the experiments performed and validated using the TLCmethod, it was determined that the procedure used in this study is reliable with specificity, accuracy, precision.

We have developed and validated the flavonoids obtain from Enhydra fluctuans. After separation of active constituents, we have got that the flavonoids are present in higher quantity as the active constituent in the plant.

\section{ACKNOWLEDGEMENT:}

Authors are thankful to Principal and Management of Bharat Technology for providing the support and permission to carry outthe work.

\section{REFERENCES:}

1. Madic SM, Males Z, Saric S, Debeljak Z, Liq J; Chromatogr. Technol. 1999; 22:82-103.

2. Jork H, Funk W, Fischer W, Wimmer H. Thin-Layer Chromatography Reagents and Detection Methods: vol 1: VCH Verlagsgesellschaftmb H, D-6940 Weinheim (Federal Republic of Germany), 1990 .p. 79-82

3. Chemistry chromatography, 2009 [cited 2009 sep 9]: Available from:http://www.marzkreations.com/Chemistry/Chromatography/Dyes/RFValues.html

4. Salunke PA, Barhate SD, Chavhan BR, Patil SS, Wagh BR, Rathod BR; Separation of Dyes by Mixed Hydrotropic Thin Layer Chromatography. Asian Journal of Pharmaceutical Analysis, 2019: DOI: https://doi.org/10.5958/2231-5675.2019.00027.9

5. Momin MAM, Khan RM, Rayhan J, Afrose A, Rana S, Begum AA;A. Ghani, Medicinal Plants of Bangladesh: Chemical Constituents \& Uses,2nd Edition, Asiatic Society of Bangladesh, Dhaka, 2003 .p. $1-16$.

6. Satyajit, Pradhan D, Natural Flavonoids Isolated from leaves of Enhydafluctuans inhibit cyclooxygenase-2 and 5, 2012; 2(1):6571.

7. Hazra, H, Alfasane, MA, Kauser S, Shahjadee UF, Khondker M; Biochemical Composition of Some Selected Aquatic Macrophytes under Ex-Situ Conditions. Journal of the Asiatic Society of Bangladesh, Science, 2018; 44(1):53-60 https://doi.org/10.3329/jasbs.v44i1.46545

8. Markham KR, Techniques of Flavonoids Identification, Academic Press, London 1982.p. 33-39

9. Wagnar H, Bladt S; Plant Drug Analysis, 2nd ed. Berlin: springer dordrechtheidelberglondon new York; 1996 .p. 195. https://doi.org/10.1007/978-3-642-00574-9

10. Feng W, Hao Z, Li M; Isolation and structure Identification of Flavonoids, China: 2017; DOI: https://doi.org/10.5772/67810

11. Mukherjee KP. Evaluating natural products and traditional medicine. 1st ed.Imprint: Elsevier; 2019; p.360-402

12. ICH Harmonised Tripartite Guideline: Validation of Analytical Procedures: Text and Methodology, Q2 (R1), ICH, Geneva, Switzerland; 2005. Available from: http://www.ich.org.

13. Nair CVJ, Ahamad S, Khan W, Anjum V, Mathur R; Development and validation of High-performance Thin-layer Chromatography Method for Simultaneous Determination of Polyphenolic Compounds in Medicinal Plants. Pharmacognosy Research, 2017; 9(1):67-73 https://doi.org/10.4103/pr.pr_122_16

14. Banavatu L; TLC slide share 2015[cited 2015 Jan 7]: Available from: https://www.slideshare.net/LavakusaBanavatu/thinlayer-chromatography-43293607

15. Bereznitski, Yuri, Thompson, Richard, Neill O, Eavan, Grinberg, Nelu. "Thin Layer Chromatography-A Useful Technique for the Separation of Enantiomers." Journal of AOAC International, 2001; 84:1242-1251.

16. Tavallali H, Zareiyan FS, Naghian M, "An efficient and simultaneous analysis of caffeine and paracetamol in pharmaceutical formulations using TLC with a fluorescence plate reader," Journal of AOAC International, 2011; 94(4):10941099. https://doi.org/10.1093/jaoac/94.4.1094

17. Seikel MK, Geissman; In The Chemistry of Flavonoid Compounds, Pergamon Press, New York, 1962; 34. 